\title{
Orthobiologic Treatment for Knee Osteoarthritis: A Cost Effectiveness Choice
}

\author{
Jose Fabio Santos Duarte Lana ${ }^{1}$, Renato Bevilacqua de Castro ${ }^{2}$, Bruno Lima Rodrigues ${ }^{1}$, Carolina Caliari \\ Oliveira*3, Stephany Cares Huber ${ }^{4}$, Nelson Foresto Lizier ${ }^{5}$, William D Murrel ${ }^{6,7}$ and Mathew Nicholls ${ }^{8}$
}

${ }^{1}$ Institute of Bone \& Cartilage, Indaiatuba SP, Brazil

${ }^{2}$ Center of Studies on Tissue Regeneration, Brazil

${ }^{3}$ In situ Cell Therapy, Brazil

${ }^{4}$ Hematology \& Hemotherapy Center, Brazil

${ }^{5}$ Department of Psychobiology, Brazil

${ }^{6}$ Emirates Healthcare, United Arab Emirates

${ }^{7}$ Emirates Integra Medical \& Surgery Centre, United Arab Emirates

${ }^{8}$ Virginia Mason Orthopedics and Sports Medicine, United States of America

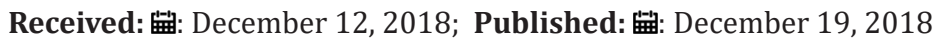

*Corresponding author: Carolina Caliari Oliveira, In situ Cell Therapy, Ribeirao Preto SP, Brazil

\begin{abstract}
Osteoarthritis (OA) is the most prevalent joint disease and a common cause of joint pain, functional loss, and disability. Besides focusing only on pain relief, conventional treatments have shown some serious adverse effects, especially with the use of corticosteroids. In the severe cases of OA, the prosthetic joint replacement is necessary. Thus, the $\mathrm{OA}$ treatment represents important economic consequences. In this way, orthobiologics are emerging as an alternative option for the treatment of knee osteoarthritis as they promote tissue regeneration. It comprises intra-articular injections of Platelet Rich Plasma, bone marrow aspirate concentrate, biofat and expanded stem cells. There has been an increasing interest in this approach over the years. Clinical trials using orthobiologics showed that when this therapy is used alone or in combination it is safe and effective in pain relief and function improvement. In addition, several in vitro studies have shown its regenerative properties. The goal of this article is to review the current options in this approach and its fundamental aspects, focusing on costs, mechanisms of action and reports of clinical trials.

Abbreviations: OA: Osteoarthritis; MMPs: Matrix Metalloproteinases; BMAC: Bone Marrow Aspirate Concentrate; AT: Adipose Tissue; SDF-1: Stromal Derived Factor; PDGF: Platelet Derived Growth Factor; HA: Hyaluronic Acid; RCT: Randomized Clinical Trial; LR-PRP: Leukocyte Rich; LPPRP: Leukocyte Poor PRP; VAS: Visual Analogic Scale IKDC: International Knee Documentation Committee; MSCs: Mesenchymal Stem Cells; HSCs: Hematopoietic Stem Cells; GMCSF: Granulocyte Macrophage Colony-Stimulating Factor;BMP-2: Bone Morphogenetic Protein; OARSI: Osteoarthritis Research Society International; SVF: Stromal Vascular Cell Fraction; AMFT: Autologous Micro fragmented Fat Tissue; FDA: Food and Drug Administration; KOOS: Knee injury and Osteoarthritis Outcome Score; IgG: Immunoglobulin G;MHC-1: Major Histocompatibility Complex; G-CSF: Granulocyte Colony-Stimulating Factor
\end{abstract}

\section{Introduction}

Knee Osteoarthritis $(\mathrm{OA})$ is one of the most prevalent joint diseases in the world. Its pathology is characterized by progressive degeneration of cartilage and bone tissue, leading to the appearance of subchondral cysts and formation of osteophytes [1,2]. Aetiological factors are also joint specific, in this context, knee $\mathrm{OA}$ is a major cause of pain and locomotor disability worldwide. Thus, knee OA patients are subject to functional loss that leads to a reduced quality of life [3]. The epidemiology of the disorder is multifactorial, however, the main risk factors for knee $\mathrm{OA}$ are overweight and obesity, previous knee injuries and female gender [3]. Besides that, the increasing of life expectancy and population aging are associated with the increased of OA incidence [4]. Beyond the personal and social consequences, the lower-limb OA, specifically hip and knee OA may have various economics consequences for patients and burdens for patients health systems in worldwide [4]. In Knee OA patiets incurred total of $\$ 9,466$ annual medical costs 
and \$2,086 annual pharmacy cost, moreover these patients had at least 1 primary knee arthroplasty with costs around $\$ 17,433$ per surgery [5]. The pathogenesis of knee OA is complex and age-related. In involves chondrocytes' poor response to growth factors, impaired bio-mechanical properties of articular cartilage, mitochondrial dysfunction, and oxidative stress. Also, a low-grade inflammation plays its role as a key mediator [6].

Histological examination of synovial fluid often indicates infiltration of inflammatory cells, involving macrophages and $\mathrm{T}$ cells, increased cell turnover and ngiogenesis $[7,8]$. The recruitment of these cells and the regulation of determined genes in the synovial membrane stimulate the production of pro-inflammatory cytokines, such as IL-1, IL-6, IL-8 and tumor necrosis factor- $\alpha$ (TNF- $\alpha$ ) [7]. High levels of pro-inflammatory cytokines stimulate synovial cells to produce and release Matrix Metalloproteinases (MMPs), known to be capable of degrading collagen type II [9]. Thus, degradation of the vascular basement membrane around the extracellular matrix (collagen) allows the migration and invasion of endothelial cells during the angiogenic process [8]. Despite the multifactorial causes, the OA Research Society International (OARSI) considers the core knee OA treatments exercises land and water-based, strength training and weight management. In addition to these biomechanical interventions, intra-articular corticosteroids injections, topical NSAIDSs, oral COX-2 inhibitors, capsaicin, oral non-selective NSAIDs, duloxetine and acetaminophen (Paracetamol) are commonly used in OA treatment [10]. Given high treatment costs and some adverse effects of these drugs, new therapeutic approaches have emerged as alternatives to treat knee OA. Amongst them, orthobiologics are found.

Orthobiologics comprise intra-articular injections of PlateletRich Plasma (PRP) as well as biografts such as Bone Marrow Aspirate Concentrate (BMAC), adipose tissue (BioFat) and stem cells [11]. Their effect is based on the ability to stimulate the healing process in $\mathrm{OA}$ as they present osteoinductive, osteoconductive and osteogenic properties. Due to its therapeutic properties, there has been an increasing interest in orthobiologics approach over the years. A PubMed search on "Orthobiologics" showed 52 publications in the last five years. These studies showed that this therapy used alone or in combination is safe and effective, as the clinical trials report pain relief, function improvement and no adverse events [12-14]. In addition, in vitro studies have shown its regenerative properties, such as decrease in local inflammation and cell apoptosis and increase in cell proliferation [39] Therefore, the goal of this article is to review the current options in orthobiologics for the clinical treatment of knee $\mathrm{OA}$.

\section{Platelet Rich Plasma}

Platelets are small cellular fragments obtained from megakaryocytes, which are involved in primary hemostasis as the main and most widely described function, but currently, researchers have evidenced other roles besides its hemostatic function [15]. Studies have shown that platelets play a key role in inflammatory and immunologic responses, which leads to an increased interest in other areas, such as regenerative medicine $[16,17]$ Platelet Rich Plasma
(PRP) is defined as a large concentration of platelets in a small volume of plasma [15]. PRP is obtained by centrifugation of a peripheral whole blood sample in which the separation of the cells and plasma is done by means of different densities [18]. It is hypothesized that the therapeutic properties of PRP act according to the presence of bioactive molecules, such as growth factors, cytokines and chemokines, which are important for biological processes [15]. Platelets are composed of alpha and dense granules, which are able to release more than 1000 active biomolecules [19]. Within the alpha granules, there are growth factors, which are the main target of studies. In the dense granules, there are some adhesion proteins, such as vitronectin, fibronectin and ADP [17].

After platelet activation, these granules fuse to the platelet membrane, causing their release. The molecules and growth factors, upon binding to the cell membrane of target cells, trigger a signaling cascade, inducing the production of proteins involved in the processes of proliferation and mitosis [20]. In PRP, activated platelets assist in tissue regeneration through the release of the Stromal Derived Factor (SDF-1), responsible for the recruitment of progenitor cells to the site of injury [21]. SDF-1, together with Vascular Endothelial Growth Factor (VEGF) and PlateletDerived Growth Factor (PDGF), also released by platelets, are indispensable for angiogenesis and vasculogenesis [22]. Thus, it is important to note that the efficacy of PRP depends on an ideal platelet concentration, buffy-coat composition, which includes a minor percentage of hematopoietic stem cells (CD34+), and SDF1 concentration [23]. Giusti et al. [22] demonstrated in an in vitro study that 1.5 - $3.0 \times 106$ platelets per microliter $(1.5-3.0 \times 106 / \mu \mathrm{l})$ was the ideal concentration to induce angiogenesis.

In contrast, from $5 \times 106$ platelets per microliter $(5 \times 106 / \mu \mathrm{l})$, an inhibition of angiogenic processes occurred. In this way, there is also a positive correlation between platelet concentration and growth factors, therefore, high platelet concentration is associated with a greater the number of growth factors [22]. In vitro studies have shown that, in addition to neutrophils, the buffy-coat layer maintains the mononuclear cells and a concentration of CD34+ cells $[24,25]$. Moreover, these cells assist the signaling pathways to other cells, secrete important biomolecules, and participate in the inflammatory process, which is crucial for the healing context $[25,26]$. Currently, there is a heterogeneity of PRP preparation protocols, which leads to a diversity of results.

There is no consensus as to the best centrifugal force or time to prepare PRP, and there are few studies attempting to classify PRP in order to standardize its products [27-31]. A standardization in the protocol and classification of PRP could facilitate the comparison between the studies [27]. Despite this discrepancy, the use of PRP in knee Osteoarthrits (OA) has been extensively investigated. A meta-analysis evaluated the efficacy and safety of intra- articular PRP injections compared with Hyaluronic Acid (HA) and saline. When compared with saline, PRP showed a significant difference six months after the injections in pain relief and improvement of joint function, and these results were maintained twelve months after the treatment. Regarding the comparison with HA, no rapid 
significant improvement was observed, contrary to what was seen with saline. However, when it was evaluated twelve months after the injections, PRP was significantly more efficacious than HA in pain relief and improvement in joint function [32].

Although it was revealed that the efficacy of PRP seemed to be higher than HA, a Randomized Clinical Trial (RCT) published by Lana et al. [12] evaluated the combination of both. It was observed that the efficacy of this association decreased pain and functional limitation and it was maintained twelve months after the treatment. Therefore, a therapy comprising a combination of PRP and HA is able to offer better outcomes than PRP or HA alone [33-35]. The presence or absence of leukocytes in PRP is a relevant point that must be considered as it can lead to different results. A meta-analysis compared clinical outcomes between the injections of Leukocyte-Rich (LR-PRP) and Leukocyte-Poor PRP (LP-PRP). The main findings were that functional scores were affected according to leukocyte concentration: The absence of leukocytes led to a better improvement. Although 6 RCT (evidence level 1) and 3 prospective comparative studies (evidence level 2) were enrolled, the authors classified the based evidence as low quality. The use of PRP was also considered a safe treatment, as no adverse events related to the product were reported [36]. Regarding the ideal number and frequency of applications, Gormeli et al. [33] stated that multiple injections of PRP are more efficacious than single injections, according to Visual Analogic Scale (VAS) of pain and IKDC score (International Knee Documentation Committee).

Furthermore, clinical results were significantly better with the use of multiple injections of PRP in early stages of knee OA, whereas no difference was seen regarding number and frequency of PRP injections for advanced OA [34]. Even though several authors suggest the use of PRP for the management of OA, there is a need for standardization in the protocol of preparation in order to avoid heterogeneous results between the studies. It is important to thoroughly report the methodology and always look for quality work with a large number of patients in order to provide answers regarding the efficacy and safety of the treatment. Despite the difficulties, there is a tendency to use PRP for knee OA, as it is considered an effective treatment in terms of pain and improvement of function, surpassing the conventional treatments available. The combination of PRP with HA is beneficial and it is an interesting therapeutic option when associating these two biological therapies.

\section{Bone Marrow Aspirate Concentrate (BMAC)}

Given that Bone Marrow Aspirate Concentrate (BMAC) is an US Food and FDA-approved method for delivering stem cells, it has been a focus of studies on musculoskeletal disorders [37]. Among other progenitor and immature cells, BMAC components comprise Hematopoietic Stem Cells (HSCs) and Mesenchymal Stem Cells (MSCs), which are precursors to hematopoietic and mesodermal lineages [38]. BMAC is often obtained by iliac crest bone marrow, which is extracted with an anticoagulant and, after centrifuged, it is concentrated in a small volume [39]. Recently, in vitro studies and clinical trials have reported the benefits of BMAC for the treatment of knee pathologies. When delivered into an injured site, it assists on cartilage regeneration and preservation by inducing the production of several growth factors, cytokines and biomolecules, such as SDF-1, Granulocyte-Macrophage Colony-Stimulating Factor (GMCSF), and bone Morphogenetic Protein (BMP)-2 and BMP-7. All these factors strengthen the healing process as they reduce local inflammation and cell apoptosis while increasing cell proliferation and differentiation via paracrine pathway [40].

Regarding knee OA, clinical trials showed that intra-articular injection of BMAC with adipose tissue scaffold reduced VAS and improved functional scores [41]. A significant association was found between higher Kellgreen-Lawrence Scale grade and inferior outcomes at follow-up. In addition, BMAC combined with PRP has also provided patient satisfaction and short-term benefits in moderate-to-severe knee $\mathrm{OA}[13,42]$. In a meta-analysis that evaluated the efficacy and safety of BMAC injections on knee OA and focal chondral defects, all studies reported that, after BMAC injections, there was an improvement in symptoms, which led to a better quality of life, especially in patients who presented advanced OA (Kellgren-Lawrence grade 4) [43]. In general, the improvement of OARSI (Osteoarthritis Research Society International) and VAS in OA patients starts one week after treatment and lasts for up to six months after BMAC injection [13]. BMAC also presents benefit in chondral lesions. Gobbi et al. [43] reported that fifty patients with grade IV showed significant improvement in activity and pain outcome scores after 2 years follow-up of receiving BMAC in a Hyaluronic Acid scaffold (HA-BMAC).

After 5 years, each patient function was characterized as normal or nearly normal [44]. The use of BMAC in chondral lesions was even superior to PRP. Krych et al. [44] evaluated forty-six patients with grades III and IV chondral lesions. These patients were divided in order to receive PRP, BMAC or control scaffolds during surgery, and they all underwent qualitative and quantitative assessment and quantitative T2 mapping one year after the procedure. While the scaffold augmented with PRP showed a similar T2 value as the control group, the BMAC group showed more cartilage fill, and the mean $\mathrm{T} 2$ value was closer to that of superficial hyaline cartilage [45]. Although the ideal number for the applications, volume, and timing of BMAC injections have not been well defined, these studies have shown that the intra-articular guided BMAC applications do not induce adverse events besides temporary joint swelling. Despite promising results, the number of clinical trials evaluating the efficacy and safety of BMAC for knee OA is considerably small and, for that reason, more studies with extensive follow-up periods are needed.

\section{BioFat Graft}

The first report of stem cells presence in adipose tissue was in 2001 [46]. Currently, the biofat graft is considered one of the greatest sources of adult stem cells, like Mesenchymal Stromal Cells (MSCs), also referred to as Adipose Derived Stem Cells (ADSCs) [47]. Therefore, it is quite promising in tissue repair and regeneration. In addition, it presents an endocrine function as it secretes hormones such as leptin, resistin, and cytokines like TNF- $\alpha$, another potential benefit of biofat is that the number of stem cells doesn't decrease 
with age like the hematopoietic-derived cells. [48]. The large number of growth factors and cytokines secreted by ADSCs, such as VEGF, HGF, Il-6, Il-7, TNF $\alpha$, M-CSF and TGF- $\beta 1$, are responsible for inducing angiogenesis, tissue remodeling, and anti-apoptotic events [49]. These cells are also capable of modulating the stem cell niche as they stimulate and recruit endogenous stem cells to the site of injury and promote their differentiation along the required lineage pathway [50].

In vitro studies using ADSCs co-cultured with allogeneic peripheral blood monocytes, have shown their ability to suppress immunoreaction as they reduce histocompatibility expression and do not stimulate a mixed lymphocyte reaction [51,52]. A similar function is seen with the use of bone marrow-derived MSCs [53]. The cells from adipose tissue can be isolated in large numbers, approximately $1 \times 106 / 200 \mathrm{~mL}$ fat from liposuction procedures [54]. A fraction of ADSCs, isolated by decantation process or by enzymatic digestion with collagenase [55], corresponds to the StromalVascular Cell Fraction (SVF), which is a heterogeneous component containing immature cells, such as pre-adipocytes, fibroblasts, vascular cells, macrophages and high amount of mesenchymal cells. A single dose of SVF (Stromal Vascular Fraction) cells induced pain relief and improvement of joint movement and stiffness until 12 months after the treatment in grade 2-4 degenerative osteoarthritis in knee and hip joints [56]. The association of vascular fraction cell therapy with exercise practices and PRP enhanced the therapeutic outcome in terms of pain relief, functional performance and quality of life improvements in patients with knee osteoarthritis $[57,58]$.

The expansion of ADSCs from adipose tissue is a relatively expensive and time-consuming process. In this sense, the SVF or the Autologous Microfragmented Fat Tissue (AMFT) may be a more suitable alternative for knee osteoarthritis patients. The AMFT is a minimal manipulation technique which complies with the FDA (Food and Drug Administration) standards. Taking that into consideration, a single intra-articular injection of AMFT was administered to 30 patients affected by diffuse degenerative chondral lesions. IKDC- subjective and total KOOS (Knee injury and Osteoarthritis Outcome Score) improvements were observed, moreover, a higher percentage of success was found in VAS pain and Tegner Lysol Knee, indicating that the use of AMFT for chondral lesions is safe and feasible [59]. Hudetz and colegues, 2017, in a prospective, non-randomized, interventional, single-center and open-label clinical trial, demonstrated that the intra-articular injection of AMFT was beneficial for knee osteoarthritis patients via MRI examinations of cartilage, Immunoglobulin G (IgG) and VAS improvement.

Additionally, the proteoglycan synthesis in hyaline cartilage was also observed [14]. Taken together, these results would indicate that the AMFT injections could be a safe and effective alternative for osteoarthritis treatment.

\section{Stem Cells}

Mesenchymal Stromal Cells (MSCs) are somatic stem cells present in small quantities in perivascular regions of all adult tissues, including bone marrow, adipose tissue, muscle tissue and parenchymal organs [60]. In a defined culture system and appropriate conditions, MSCs exhibit fibroblast-like morphology and can differentiate into and giving rise to osteoblasts, chondroblasts and adipocytes, among others. Due to the low frequency of MSCs in primary tissue, the expansion of this stem cell population is critical and helps to enable basic biological studies and clinical research. However, MSCs can only be expanded in a limited number of times, since long-term culture reduces its proliferation and potential differentiation and increases the risk of tumorigenesis. An additional important consideration at this point is that MSCs derived from from different patients u s i $\mathrm{n} \mathrm{g}$ identical culture conditions display significant differences in colony morphology, differentiation potential and gene expression $[61,62]$.

MSCs must present the following phenotypic pattern: CD73+, CD90+, CD105+ and lack hematopoietic cell markers: CD45-, CD34-, CD14- or CD11b-, CD79- or CD19-. Furthermore, in regard to immunomodulatory effects, MSCs express smallamounts of Major Histocompatibility Complex (MHC-I) and negligible levels or non- expression of MHC-II on their surface [63]. In this way, these cells would be tolerated by the recipient organism. Also, cell-cell contact causes MSCs to produce different types of soluble growth factors, including Granulocyte Colony-Stimulating Factor (G-CSF), Granulocyte-Macrophage Colony-Stimulating Factor (GM-CSF), Macrophage Colony-Stimulating Factor (M-CSF), Transforming Growth Factor Beta (TGF- $\beta$ ) and various interleukin (IL-6, IL-10 and TGF- $\beta$ ), which influence cells involved in the inflammation process [64]. Recently, Caplan proposed an alteration in the term 'MSCs' based on their current therapeutic use and paracrine activities. MSCs should be an acronym for "medicinal signaling cells" [65].

Consequently, this characteristic was enthusiastically received in the hope that these would become an alternative to embryonic stem cells and free of the ethical implications associated with their therapeutic application [66]. Most small-sized clinical trials conducted with MSCs in regenerative medicine applications has not reported major health concerns, suggesting that MSCs therapies could be relatively safe [67]. In terms of chondrogenic potential of MSCs, most in vivo studies employed the use of defect models that are delimited by healthy cartilage and thus would simulate cartilage injury and mask MSC action. In osteoarthritis-associated cartilage lesions that are delimited by degenerative cartilage, the real action of MSCs can be measured, because it is known that MSCs home in on and are also preferentially attracted to diseased tissue rather than healthy tissue [68]. There are not many reports on clinical outcomes of intra-articular injection of MSCs, but some authors have demonstrated that MSCs attach to cartilage defects, proliferate, participate in the regeneration of articular cartilage [69-73] and retard the progression of osteoarthritis [74,75]. Although most of the studies were performed in an animal model, these results suggest that MSCs should be delivered into the lesion for better outcomes and also clarified in order to achieve balanced efficacy and safety [69]. Jo et al. [67] in a phase one trial proof of concept performed intra-articular injection of autologous Adipose Tissue derived MSCs (AD-MSCs) in 18 patients with knee 
osteoarthritis. The authors observed no treatment-related adverse events. Additionally, 6 months after injection, the patients who received the highest numbers of cells showed better WOMAC scores with decrease in cartilage defect, increased cartilage volume in the condyles and hyaline-like cartilage regeneration. This indicates that the AD-MSCs were safe and effective in knee OA treatment [69].

That clinical and structural outcomes evaluated with MRI remained until 1 year after treatment in patients that received low and medium-doses of AD-MSCs, while the high-dose group patient outcomes lasted until 2 years [76]. The association of PRP and MSCs was beneficial in knee OA patients. The safety of the treatment was showed, as minimal adverse effects were seen in patients submitted to intra-articular injections of MSCs or MSCs+PRP and, besides that, these patients showed a tendency of improvements in function, pain, daily and recreational activities at 12-month endpoint [77]. Despite the small number of treated patients and the small amount of RCTs, the outcomes for MSC treatments in knee $\mathrm{OA}$ are encouraging since they may represent an effective and less invasive treatment for these patients.

\section{Conclusion}

The beneficial effect of orthobiological treatment for musculoskeletal disorders was demonstrated in many basic science experiments and clinical trials. In these investigations, the orthobiological treatment remains superior over other established surgical and non-surgical treatments. However, larger randomized clinical trials may allow better characterization of the orthobiological mechanisms in musculoskeletal pathologies.

\section{References}

1. Sharma AR, Jagga S, Lee SS, Nam JS (2013) Interplay between cartilage and subchondral bone contributing to pathogenesis of osteoarthritis. Int J Mol Sci 14(10): 19805-19830.

2. Amoako AO, Pujalte GGA (2014) Osteoarthritis in young, active, and athletic individuals. Clin Med Insights Arthritis Musculoskelet Disord 7: 27-32.

3. Silverwood V, Blagojevic Bucknall M, Jinks C, Jordan JL, Protheroe J, et al. (2015) Current evidence on risk factors for knee osteoarthritis in older adults: A systematic review and meta-analysis. Osteoarthr Cartil 23(4): 507-515.

4. Salmon JH, Rat AC, Sellam J, Michel M, Eschard JP, et al. (2016) Economic impact of lower-limb osteoarthritis worldwide: a systematic review of cost-of-illness studies. Osteoarthr Cartil 24(4):1500-1508.

5. Wang SX, Ganguli AX, Macaulay D, Reichmann W, Medema JK, et al. (2014) The economic burden of osteoarthritis in Americans: analysis from a privately insured population. Osteoarthr Cartil 22: S210.

6. Siebuhr AS, Bay Jensen AC, Jordan JM, Kjelgaard Petersen CF, Christiansen $C$, et al. (2016) Inflammation (or synovitis)-driven osteoarthritis: An opportunity for personalizing prognosis and treatment? Scand J Rheumatol 45(2): 87-98.

7. Klein Wieringa IR, de Lange Brokaar BJE, Yusuf E, Andersen SN, Kwekkeboom JC, et al. (2016) Inflammatory Cells in Patients with Endstage Knee Osteoarthritis: A Comparison between the Synovium and the Infrapatellar Fat Pad. J Rheumatol 43(4): 771-778.

8. Mongiat M, Andreuzzi E, Tarticchio G, Paulitti A (2016) Extracellular matrix, a hard player in angiogenesis. Int J Mol Sci 17(11): 1822.
9. Martel PJ, Raynauld JP, Mineau F, Abram F, Paiement P, et al. (2017) Levels of serum biomarkers from a two-year multicentre trial are associated with treatment response on knee osteoarthritis cartilage loss as assessed by magnetic resonance imaging: an exploratory study. Arthritis Res Ther 19: 169.

10. McAlindon TE, Bannuru RR, Sullivan MC, Arden NK, Berenbaum F, et al. (2014) OARSI guidelines for the non-surgical management of knee osteoarthritis. Osteoarthr Cartil 22(3): 363-388.

11. Sampson S, Vincent H, Aufiero D (2016) Intra-articular bone marrow concentrate injection protocol: short-term efficacy in osteoarthritis. Regen Med 11(6): 511-520.

12. Lana JFSD, Weglein A, Sampson SE, Vicente EF, Huber SC, et al. (2016) Randomized controlled trial comparing hyaluronic acid, plateletrich plasma and the combination of both in the treatment of mild and moderate osteoarthritis of the knee. J Stem Cells Regen Med 12(2): 6978.

13. Shapiro SA, Kazmerchak SE, Heckman MG, Zubair AC, O Connor MI, et al. (2016) A Prospective, Single-Blind, Placebo-Controlled Trial of Bone Marrow Aspirate Concentrate for Knee Osteoarthritis. Am J Sports Med 45(1): 82-90.

14. Hudetz D, Boric I, Rod E, Jelec Z, Radic A, Vrdoljak T, et al. (2017) The effect of intra-articular injection of autologous microfragmented fat tissue on proteoglycan synthesis in patients with knee osteoarthritis. Genes (Basel) p. 8.

15. Miao Y, Sun Y Bin, Sun XJ, Du BJ, Jiang JD, et al. (2013) Promotional effect of platelet-rich plasma on hair follicle reconstitution in vivo. Dermatologic Surg 39(12): 1868-1876.

16. Tolga Fikret Tozum, Demiralp B (2011) Platelet-Rich Plasma (PRP). OrthoInfo p. 20-24.

17. Okuda K, Kawase T, Momose M, Murata M, Saito Y, et al. (2003) PlateletRich Plasma Contains High Levels of Platelet-Derived Growth Factor and Transforming Growth Factor- $\beta$ and Modulates the Proliferation of Periodontally Related Cells In Vitro. J Periodontol 74(6): 849-857.

18. Amable PR, Carias RBV, Teixeira MVT, Da Cruz Pacheco Í, Correa Do Amaral RJF, et al. (2013) Granjeiro JM, et al. Platelet-rich plasma preparation for regenerative medicine: Optimization and quantification of cytokines and growth factors. Stem Cell Res Ther 4(3): 1-13.

19. Coppinger JA, Cagney G, Toomey S, Kislinger T, Belton O, et al. (2012) Characterization of the proteins released from activated platelets leads to localization of novel platelet proteins in human atherosclerotic lesions. Blood 103: 2096-2104.

20. Andia I, Abate M (2013) Platelet-rich plasma: underlying biology and clinical correlates. Regen Med 8(5): 645-658.

21. Jin DK, Shido K, Kopp HG, Petit I, Shmelkov S V, et al. (2006) Cytokinemediated deployment of SDF-1 induces revascularization through recruitment of CXCR4+hemangiocytes. Nat Med 12: 557-567.

22. Giusti I, Rughetti A, D Ascenzo S, Millimaggi D, Pavan A, et al. (2009) Identification of an optimal concentration of platelet gel for promoting angiogenesis in human endothelial cells. Transfusion 49(4): 771-778.

23. Tang JM, Wang JN, Zhang L, Zheng F, Yang JY, et al. (2011) VEGF/SDF-1 promotes cardiac stem cell mobilization and myocardial repair in the infarcted heart. Cardiovasc Res 91(3): 402-411.

24. Sundman EA, Cole BJ, Fortier LA (2011) Growth factor and catabolic cytokine concentrations are influenced by the cellular composition of platelet-rich plasma. Am J Sports Med 39(10): 2135-2140.

25. Cesselli D, Beltrami AP, Rigo S, Bergamin N, D Aurizio F, et al. (2009) Multipotent progenitor cells are present in human peripheral blood. Circ Res 104: 1225-1234. 
26. Sundman EA, Cole BJ, Fortier LA (2011) Growth Factor and Catabolic Cytokine Concentrations Are Influenced by the Cellular Composition of Platelet-Rich Plasma. Am J Sports Med p. 1-6.

27. Lana JFSD, Purita J, Paulus C, Huber SC, Rodrigues BL, et al. (2017) Contributions for classification of Platelet Rich Plasma - proposal of a new classification: MARSPILL. Regen Med 12(5): 565-574.

28. Dohan EDM, Rasmusson L, Albrektsson T (2009) Classification of platelet concentrates: from pure platelet-rich plasma (P-PRP) to leucocyte- and platelet-rich fibrin (L-PRF). Trends Biotechnol 27(3): 158-167.

29. Delong JM, Russell RP, Mazzocca AD (2012) Platelet-rich plasma: The PAW classification system. Arthroscopy. 28(7): 998-1009.

30. Mautner K, Malanga GA, Smith J, Shiple B, Ibrahim V, et al. (2015) A Call for a Standard Classification System for Future Biologic Research: The Rationale for New PRP Nomenclature. PMR 7: 53-59.

31. Dai WL, Zhou AG, Zhang H, Zhang J (2017) Efficacy of Platelet-Rich Plasma in the Treatment of Knee Osteoarthritis: A Meta-analysis of Randomized Controlled Trials. Arthroscopy 33(3): 659-670.

32. Raeissadat SA, Rayegani SM, Ahangar AG, Abadi PH, Mojgani P, et al. (2017) Efficacy of Intra-articular Injection of a Newly Developed Plasma Rich in Growth Factor (PRGF) Versus Hyaluronic Acid on Pain and Function of Patients with Knee Osteoarthritis: A Single-Blinded Randomized Clinical Trial. Clin Med Insights Arthritis Musculoskelet Disord 10: 1-9.

33. Gormeli G, Ays C, Ataoglu B, Çolak C, Aslanturk O, et al. (2015) Multiple PRP injections are more effective than single injections and hyaluronic acid in knees with early osteoarthritis: a randomized, double - blind, placebo - controlled trial. Knee Surg Sport Traumatol Arthrosc 25(3): 958-965.

34. Cole BJ, Karas V, Hussey K, Merkow DB, Pilz K, et al. (2017) Hyaluronic Acid Versus Platelet-Rich Plasma: A Prospective, Double-Blind Randomized Controlled Trial Comparing Clinical Outcomes and Effects on Intra-articular Biology for the Treatment of Knee Osteoarthritis. Am J Sports Med 45(2): 339-346.

35. Riboh JC, Saltzman BM, Yanke AB, Fortier L, Cole BJ, et al. (2015) Effect of Leukocyte Concentration on the Efficacy of Platelet-Rich Plasma in the Treatment of Knee Osteoarthritis. Am J Sports Med 44(3): 792-800.

36. Chahla J, Dean CS, Moatshe G, Pascual Garrido C, Serra Cruz R, et al. (2016) Concentrated Bone Marrow Aspirate for the Treatment of Chondral Injuries and Osteoarthritis of the Knee: A Systematic Review of Outcomes. Orthop J Sport Med 4(1): 2325967115625481.

37. Hosseinkhani M, Mehrabani D, Karimfar MH, Bakhtiyari S, Manafi A, et al. (2014) Tissue engineered scaffolds in regenerative medicine. World J Plast Surg 3(1): 3-7.

38. Hernigou P, Homma Y, Henri C, Lachaniette F, Poignard A, et al. (2013) Benefits of small volume and small syringe for bone marrow aspirations of mesenchymal stem cells. Int Orthop 37(11): 2279-2287.

39. Madry H, Gao L, Eichler H, Orth P, Cucchiarini M, et al. (2017) Bone Marrow Aspirate Concentrate-Enhanced Marrow Stimulation of Chondral Defects. Stem Cells Int p. 13.

40. Kim J Do, Lee GW, Jung GH, Kim CK, Kim T, et al. (2014) Clinical outcome of autologous bone marrow aspirates concentrate (BMAC) injection in degenerative arthritis of the knee. Eur J Orthop Surg Traumatol 24(8): 1505-1511.

41. Sampson S, Smith J, Vincent H, Aufiero D, Zall M, et al. (2016) Intraarticular bone marrow concentrate injection protocol: short-term efficacy in osteoarthritis. Regen Med 11(6): 511-520.

42. Chahla J, Cinque ME, Shon JM, Liechti DJ, Matheny LM, et al. (2016) Bone marrow aspirate concentrate for the treatment of osteochondral lesions of the talus: a systematic review of outcomes. J Exp Orthop. 3: 33.

43. Gobbi A, Whyte GP (2016) One-Stage Cartilage Repair Using a Hyaluronic Acid-Based Scaffold with Activated Bone Marrow-Derived Mesenchymal
Stem Cells Compared with Microfracture. Am J Sports Med 44(11): 2846-2854.

44. Krych AJ, Nawabi DH, Farshad amacker NA, Jones KJ, Maak TG, et al. (2016) Bone Marrow Concentrate Improves of a Scaffold Plug in the Knee. Am J Sports Med 44(1): 89-91.

45. Zuk PA, Zhu M, Mizuno H, Huang J, Futrell JW, et al. (2017) Multilineage Cells from Human Adipose Tissue: Implications for Cell-Based Therapies. Tissue Eng 7(2): 211-228.

46. Witkowska ZM, Walenko K (2011) Stem cells from adipose tissue. Cell Mol Biol Lett 16(2):236-257.

47. Kershaw EE, Flier JS (2004) Adipose tissue as an endocrine organ. J Clin Endocrinol Metab 89(6):2548-2456.

48. Kilroy GE, Foster SJ, Wu X, Ruiz J, Sherwood S, et al. (2006) Cytokine Profile of Human Adipose-Derived Stem Cells: Expression of Angiogenic, Hematopoietic, and Pro-Inflammatory Factors. J Cell Physiol 212(3): 702-709.

49. Gimble JM, Katz AJ, Bunnell BA (2007) Adipose-derived stem cells for regenerative medicine. Circ Res 100: 1249-1260.

50. Puissant B, Barreau C, Bourin P, Clavel C, Corre J, et al. (2005) Immunomodulatory effect of human adipose tissue-derived adult stem cells: comparison with bone marrow mesenchymal stem cells. $\mathrm{Br} \mathrm{J}$ Haematol 129(1): 118-129.

51. McIntosh K, Zvonic S, Garrett S, Mitchell JB, Floyd ZE, et al. (2006) The immunogenicity of human adipose-derived cells: temporal changes in vitro. Stem Cells 24: 1246-1253.

52. Bartholomew A, Sturgeon C, Siatskas M, Ferrer K, McIntosh K, et al. (2002) Mesenchymal stem cells suppress lymphocyte proliferation in vitro and prolong skin graft survival in vivo. Exp Hematol 30(1): 42-48.

53. Zhu Y, Liu T, Song K, Fan X, Ma X, et al. (2007) Adipose-derived stem cell: a better stem cell than BMSC. Cell Biochem Funct 26(6): 664-675.

54.Williams SK, McKenney S, Jarrell BE (1995) COLLAGENASE LOT SELECTION AND PURIFICATION FOR ADIPOSE TISSUE DIGESTION. Cell Transplant 4(3): 281-289.

55. Michalek AJ, Moster R, Lukac L, Proefrock K (2015) Autologous adipose tissue-derived stromal vascular fraction cells application in patients with osteoarthritis. Cell Transplant p. 1-36.

56. Gibbs N, Diamond R, Sekyere EO, Thomas DW (2015) Management of knee osteoarthritis by combined stromal vascular fraction cell therapy, platelet-rich plasma and musculoskeletal exercises: a case series. J Pain Res 8: 799-806.

57. Pak J, Lee JH, Park KS, Park M, Kang LW, et al. (2017) Current use of autologous adipose tissue-derived stromal vascular fraction cells for orthopedic applications. J Biomed Sci 24: 9.

58. Russo A, Condello V, Madonna V, Guerriero M, Zorzi C, et al. (2017) Autologous and micro-fragmented adipose tissue for the treatment of diffuse degenerative knee osteoarthritis. J Exp Orthop 4: 33.

59. Filho STLP, Treichel TLE, JSA, Rosa MB da, Dalmolin F, et al. (2013) Células-Tronco mesenquimais adultas: Características e aplicações experimentais em animais. Veterinária e Zootec 20: 49-59.

60. Meirelles S, Chagastelles PC, Nardi NB (2006) Mesenchymal stem cells reside in virtually all post-natal organs and tissues. J Cell Sci 119(pt 11): 2204-2213.

61. Kaltz N, Ringe J, Holzwarth C, Charbord P, Niemeyer M, et al. (2010) Novel markers of mesenchymal stem cells defined by genome-wide gene expression analysis of stromal cells from different sources. Exp Cell Res 316(16): 2609-2617.

62. Dominici M, Le Blanc K, Mueller I, Slaper CI, Marini F, et al. (2006) Minimal criteria for defining multipotent mesenchymal stromal cells. The International Society for Cellular Therapy position statement. Cytotherapy 8(4): 315-357. 
63. Meirelles LDS, Fontes AM, Covas DT, Caplan AI (2009) Mechanisms involved in the therapeutic properties of mesenchymal stem cells. Cytokine Growth Factor Rev 20(5-6): 419-427.

64. Caplan AI (2017) Mesenchymal stem cells: Time to change the name! Stem Cells Transl Med 6(6):1445-1451.

65. Nombela Arrieta C, Ritz J, Silberstein LE (2012) The elusive nature and function of mesenchymal stem cells. Nat Rev Mol Cell BiolNat Rev Mol Cell Biol 12(2): 126-1231.

66. Herberts CA, Kwa MS, Hermsen HP (2011) Risk factors in the development of stem cell therapy. J Transl Med 9: 29.

67. Jo C, Lee Y, SHIN W (2014) Intra-Articular Injection of Mesenchymal Stem Cells for the Treatment of Osteoarthritis of the Knee: A Proof-ofConcept Clinical Trial. Stem Cells 32(5): 1254-1266.

68. Mokbel AN, El Tookhy OS, Shamaa AA, Rashed LA, Sabry D, et al. (2011) Homing and reparative effet of intra-articular injection of autologous mesenchymal stem cells in osteoarthritic animal model. BMC Musculoskelet Disord 12: 259.

69. Sato M, Uchida K, Nakajima H, Miyazaki T, Guerrero AR, et al. (2012) Mesenchymal Stem Cells Transplantation to the Knee Joint of Hartley Strain Guinea Pig with Spontaneous Osteoarthritis. Arthritis Res Ther 14(1): R31.

70. Frisbie DD, Kisiday JD, Kawcak CE, Werpy NM, Mcllwraith CW, et al. (2009) Evaluation of adipose-derived stromal vascular fraction or bone

\section{ISSN: 2574-1241}

DOI: 10.26717/BJSTR.2018.12.002243

Carolina Caliari Oliveira. Biomed J Sci \& Tech Res

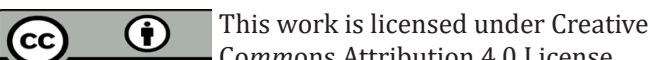

Submission Link: https://biomedres.us/submit-manuscript.php marrow-derived mesenchymal stem cells for treatment of osteoarthritis. J Orthop Res 27(12): 1675-1680.

71. Lee KBL, Hui JHP, Song IC, Ardany L, Lee EH (2007) Injectable Mesenchymal Stem Cell Therapy for Large Cartilage Defects-A Porcine Model. Stem Cells 25(11): 2964-2971.

72. Murphy JM, Fink DJ, Hunziker EB, Barry FP (2003) Stem Cell Therapy in a Caprine Model of Osteoarthritis. Arthritis Rheum 48(12): 3464-3474.

73. Al Faqeh H, Nor Hamdan BMY, Chen HC, Aminuddin BS, Ruszymah BHI, et al. (2012) The potential of intra-articular injection of chondrogenicinduced bone marrow stem cells to retard the progression of osteoarthritis in a sheep model. Exp Gerontol 47(6): 458-464.

74. Jo CH, Chai JW, Jeong EC, Oh S, Shin JS, et al. (2017) Intra-articular Injection of Mesenchymal Stem Cells for the Treatment of Osteoarthritis of the Knee: A 2-Year Follow-up Study. Am J Sports Med 45(12): 27742783.

75. Bastos R, Mathias M, Andrade R, Bastos R, Balduino A, Schott V, et al. (2018) Intra-articular injections of expanded mesenchymal stem cells with and without addition of platelet-rich plasma are safe and effective for knee osteoarthritis. Knee Surgery, Sport Traumatol Arthrosc 26(11): 3342-3350.

76. Li Y, Wei X, Zhou J, Wei L (2013) The age-related changes in cartilage and osteoarthritis. BioMed research international.

\begin{tabular}{ll} 
BIOMEDICAL & Assets of Publishing with us \\
RESEARCHES & - Global archiving of articles \\
\hline IsSN: 2574-1241 & - Immediate, unrestricted online access \\
\hline
\end{tabular}

